\title{
Editorial \\ Ciência, Poesia e Editoração Científica
}

\author{
Passado... presente \\ Ondas que vêm, deixam espumas, \\ Carregam lembranças num mar revolto... \\ Doces algumas, tão suaves! \\ Mal chegam no roçar da consciência... \\ Se engancham em outras, formam correntes \\ E um jorro quente de saudade. \\ A cor que passa no horizonte, o tom de voz. \\ Que se dilui antes que eu o arrebanhe, \\ o perfume desfeito da alegria ingênua... \\ Voltar no tempo... \\ Soltar as amarras que nos prendem ao presente \\ E vagar onde quer que as emoções se mostrem \\ Doces, amenas... \\ Caminhar por sobre o tempo \\ E se instalar lá atrás... \\ Vendo o desfilar sem fim, sem pressa, \\ Dos afetos que o coração guardou \\ Zélia Maria \\ (Biasoli-Alves, 1996, p. 10)
}

Com poesia e nostalgia inicio a apresentação deste número, certa de que arte e ciência são perfeitamente amalgamáveis quando se tem espírito criativo, inovador e arrojado. É o que nos atestou em vida a nossa já saudosa Profa. Zélia Biasoli-Alves, inspiradora deste editorial.

Vimos assistindo nos últimos tempos os reflexos que o ritmo vertiginoso de mudanças no âmbito das ciências da informação têm produzido sobre o rumo da editoração científica. Paralelamente a essas transformações, houve um crescimento exponencial de periódicos nos mais diversos campos do conhecimento que, por sua vez, originaram iniciativas de apreciação sistemática das revistas brasileiras. Os ditames de qualidade na produção, por usa vez, têm se deslocado do referencial de números de artigos publicados para o que vem sendo chamado de fator de impacto, isto é, número de citações que os artigos recebem. Essa medida pode ser perfeitamente plausível em diversas áreas do conhecimento, mas é necessária uma profunda e criteriosa discussão para avaliar os seus reflexos sobre a produção científica brasileira na área de ciências humanas e sociais.

$\mathrm{Na}$ arte da editoração científica, os desafios e descompassos no processo de adaptação às frenéticas mudanças nos remetem, por vezes, ao desejo de aceitar o convite de "soltar as amarras do que nos prendem ao presente" e "voltar no tempo..." A revista Psicologia: Teoria e Pesquisa tem se esforçado para que esse ritual de passagem não acarrete traumas de nenhuma natureza. Nossos leitores já vêm acompanhando as mudanças graduais ocorridas nos dois últimos anos e não hão de se surpreender com algumas das inovações resultantes. Nesse particular, o processo de tramitação eletrônica é um de nossos maiores desafios. Reiteramos aqui a nossa recomendação de que toda submissão de manuscrito candidato a publicação em nossa revista deva ser feita eletronicamente por meio da plataforma SEER (www.revistaptp.unb.br).
Como já é de tradição da revista, neste número procurouse oferecer ao leitor uma gama sortida da produção brasileira e estrangeira em Psicologia e áreas afins, no intuito de fornecer um panorama global da produção teórico-metodológica e técnica atual e atender à necessidade de comunicação científica nesse campo do conhecimento. Assim sendo, apresentam-se aqui artigos nas áreas do desenvolvimento humano, psicologia da saúde, psicologia jurídica, psicologia da personalidade, neuropsicologia, psicometria, psicoterapia, psicanálise e história da psicologia.

Neste número, por ironia do destino e como presente divino, a Profa. Zélia Biasoli-Alves nos agraciou com um de seus últimos trabalhos em co-autoria com Lígia Ebner, Dayana Souza e Maria Aparecida Bugliani, no qual abordam o julgamento de mães e educadoras de berçários sobre os fatores que influenciam o temperamento e o desempenho do bebê. Ainda na área do desenvolvimento infantil, César Piccinini, Caroline Pereira, Ângela Marin, Rita Lopes e Jonathan Tudge investigam o impacto do nascimento do segundo filho nas relações familiares, redes de apoio, relação conjugal e comportamentos do primogênito.

Normanda de Morais, Elder Cerqueira-Santos, Andreína Vaz e Silvia Koller tratam da questão da exploração sexual comercial de crianças e adolescentes na perspectiva do abusador, no intuito de oferecer perspectivas de enfrentamento mais eficazes da questão.

O estudo do desenvolvimento locomotor de crianças e adultos em ambientes domésticos é tratado no artigo de Lílian Gobbi, Jean Silva, Ana Clara Paiva e Priscila Scabello. Por sua vez, Angélica Paiva e Silva, Maria Cristina Pereira e Maria de Lourdes Zanolli apresentam um estudo sobre a relação entre a escolha da modalidade de linguagem por parte de mães de crianças surdas e as concepções que essas mães têm sobre a surdez.

Os fatores associados aos problemas da adolescência são tratados em artigo de Jiovani Avanci, Simone Assis, Raquel Oliveira, Renata Ferreira e Renata Pesce, a partir de um estudo epidemiológico com alunos de escolas públicas e particulares do município de São Gonçalo, RJ.

Márcia Bandeira e Valéria Barbieri apresentam um estudo sobre a influência de características gerais de personalidade na formação de câncer de mama e de aparelho digestório em mulheres. Ainda quanto ao estudo da influência de traços de personalidade, a interação entre extroversão e introversão e o conhecimento astrológico de estudantes universitários é tratada no artigo de Anna Pacheco, Chaves Nagelsmidt e Paulo Rodrigues.

Vera Figueiredo e Elizabeth Nascimento avaliam o desempenho e a discrepância em dois dos subtestes da bateria WISC e WAIS-III na avaliação da memória de trabalho e da atenção em amostras brasileiras. Por seu turno, Natanael dos Santos, Adriana Oliveira, Renata Nogueira, Melyssa Cavalcanti e Maria Lúcia Simas apresentam um estudo sobre percepção visual e sensibilidade ao contraste em adultos e idosos.

Um estudo documental sobre o conceito de resiliência e sua contribuição para o indivíduo idoso é apresentado 
no artigo de Carlos Laranjeira. No artigo de Maria Leonor Enéas - que também utiliza como base o estudo documental -, a autora propõe-se a verificar as tendências de pesquisas na área de psicoterapia no período de 1995 a 2005 e constata que as mesmas têm centrado seu foco nos ensaios clínicos controlados. Ainda na área de psicologia clínica, Veridiana Guimarães e Luiz Celes discutem o conceito metapsicológico de identificação - que inclui elementos psíquicos e sociais - , com base na teoria psicanalítica.

Em seu artigo, Maurício Neubern apresenta um estudo teórico no qual desenvolve uma reflexão crítica e epistemológica sobre o processo de condenação do magnetismo animal na história da psicologia.

Uma resenha do livro de Mussini sobre o papel da família na prevenção ao uso indevido de drogas é apresentada por Eduardo Silva e Fabrício Guimarães.

Na seção de notícias, temos a contribuição de Maria Helena de Freitas que apresenta uma notícia sobre o VI
Seminário Psicologia e Senso Religioso ocorrido em agosto último em São Paulo e a notícia de 50 anos de morte de Reich por Sara Mathiesen.

Por último, este número traz a homenagem prestada por Cláudia Martinez, Maria Helena da Silva, Neucideia Colnago, Regina Caldana e Silvia Sigolo a nossa querida professora Zélia, falecida em 11 de julho deste ano, e que nos deixou um rico legado de produções científicas e poéticas.

Aos nossos caros leitores, desejo uma ótima leitura.

\section{Referência}

Biasoli-Alves, Z. M. M. (1996). Memórias, brincadeiras e poesias... ...em duas gerações dos Mendes Biasoli. Ribeirão Preto: Regis Summa.

\section{Conselho Editorial (2006 - 2008)}

Adriana Wagner (PUC-RS)

Ana Cristina Costa de Figueiredo (UFRJ)

Ângela Maria de Oliveira Almeida (UnB)

Antonio Pedro de Mello Cruz (UnB)

Domingos Sávio Coelho (UnB)

Emmanuel Zagury Tourinho (UFPA)

Eveline Maria Leal Assmar (UGF)

Gérson Aparecido Yukio Tomanari (USP)

Leandro de Lajonquière (USP)

Lúcia Rabello de Castro (UFRJ)

Maria Izabel Tafuri (UnB)

Mário César Ferreira (UnB)

Tereza Cristina Cavalcanti Ferreira de Araújo (UnB)

Terezinha de Camargo Viana (UnB)

Valdiney Veloso Gouveia (UFPB)

Wanderley Codo (UnB) 